\title{
Eruptif Ksantomla Ortaya Çıkan Tip 2 Diabetes Mellitus ve Obeziteli Bir Ağır Hipertrigliseridemi Olgusu
}

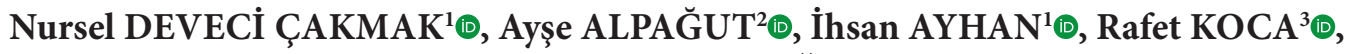 \\ Taner BAYRAKTAROĞLU ${ }^{1,4}{ }^{-1}$ \\ 'Zonguldak Bülent Ecevit Üniversitesi Tip Fakültesi, İç Hastalıkları Anabilim Dalı, Zonguldak \\ ${ }^{2}$ Zonguldak Bülent Ecevit Üniversitesi Tip Fakültesi, Dönem IV, Zonguldak \\ ${ }^{3}$ Zonguldak Bülent Ecevit Üniversitesi Tıp Fakültesi, Deri ve Zührevi Hastalıkları Anabilim Dalı, Zonguldak \\ ${ }^{4}$ Zonguldak Bülent Ecevit Üniversitesi Tıp Fakültesi, Endokrinoloji ve Metabolizma Hastalıkları Bilim Dalı, Zonguldak
}

Bu makaleye yapılacak atıf: Deveci Çakmak N, Alpağut A, Ayhan İ, Koca R, Bayraktaroğlu T. Eruptif Ksantomla Ortaya Çıkan Tip 2 Diabetes Mellitus ve Obeziteli Bir Ağır Hipertrigliseridemi Olgusu. Türk Diyab Obez 2018;3: 125-128.

\begin{abstract}
ÖZET
Hipertrigliseridemi, obezite ve hipotiroidizm gibi sekonder nedenler haricinde genetik lipid bozuklukları şeklinde ortaya çıkmaktadır. Farklı klinik prezantasyonları bulunmasına rağmen erişkin dönemde nadiren eruptif ksantom bulgusuyla hipertrigliseridemi olguları tanı alır. Burada, şizofreni tanısıyla izlenirken ciltte döküntüleriyle birlikte diabetes mellitus ve belirgin hipertrigliseridemi tanısı alan bir olguyu sunmaktayız.

Olgumuzda da görüldüğü gibi hiperlipidemiler genetik alt yapısı müsait bireylerde obezite, diabetes mellitus ve antipsikotiklerle belirgin ortaya çıkabilirler. Prezantasyonları nadir bir bulgu olan eruptif ksantomlar şeklinde olabilir. Bu gibi olgulara metabolik yolaklara yönelik çok yönlü yaklaşımla lipid aferezi gerektirmeden etkin sonuçlar elde edilebilir.

Anahtar Sözcükler: Eruptif Ksantom, Hiperlipidemi, Hipertrigliseridemi, Obezite, Diabetes Mellitus, Şizofreni, Antipsikotikler
\end{abstract}

\section{A Case of Severe Hypertrigliseridemia Presentation with Eruptive Xantoma in an Adult with Type-2 Diabetes Mellitus and Obesity}

\begin{abstract}
Hypertriglyceridemia occurs as genetic lipid disorders with the exception of secondary causes such as obesity and hypothyroidism. Although there are different clinical presentations, hypertriglyceridemia cases are rarely seen in adulthood with the presence of eruptive xanthoma. Here, we present a case with schizophrenia diagnosed with skin rashes and diabetes mellitus and severe hypertriglyceridemia. As seen in our case, hyperlipidemias may occur with obesity, diabetes mellitus and antipsychotics in individuals with genetic background. Their presentation may be in the form of eruptive xanthomas, a rare finding. In such cases, effective results can be obtained with a multifaceted approach to metabolic pathways without requiring lipid apheresis.
\end{abstract}

Key Words: Eruptive Xanthoma, Hyperlipidemia, Hypertriglyceridemia, Obesity, Diabetes Mellitus, Schizophrenia, Antipsychotics

30 Kasım-1 Aralık 2018 tarihlerinde III. Zonguldak Endokrin Günleri, Uluslararası ve Ulusal Katılımlı Multidisipliner Güncel Yaklaşım Sempozyumunda Poster Bildirisi olarak sunulmuştur.

ORCID: Nursel Deveci Çakmak / 0000-0002-2170-4969, Ayșe Alpağut / 0000-0001-5804-9403, İhsan Ayhan / 0000-0002-7539-2454, Rafet Koca / 0000-0003-1546-5380 Taner Bayraktaroğlu / 0000-0003-3159-6663 


\section{AMAC}

Hipertrigliserideminin, özellikle son zamanlarda, kardiyovasküler hastalık (KVH) gelişimi için başlı başına bir risk faktörü olduğunun belirlenmesi, ayrıca yıllardan beri akut non-bilier pankreatit ve non-alkolik steatohepatitin etiyopatogenezinde önemli rol oynadığının bilinmesi, tedavi edilmesinin gerekliliğini ortaya koymaktadır. Sekonder hipertrigliseridemiden ise obezite, diabetes mellitus, hipotiroidi,nefrotik sendrom, sedanter yaşam gibi nedenler sorumlu tutulmaktadır. Hipertrigliseridemi, genetik lipid bozuklukları dışında obezite ve hipotiroidizm gibi sekonder nedenler de ortaya çıkarmaktadır. Ayrıca birçok ilacın lipid metabolizması üzerinde ciddi etkileri vardır ve lipoprotein profilinde ciddi değişiklikler ile sonuçlanabilir. Tiazid gibi diüretikler, selektif olmayan beta blokerler, antipsikotikler, östrojen preparatları, tamoksifen, steroidler, izotretinoin, proteaz inhibitörleri ve nükleozid analogları gibi ilaçlar trigliserid yüksekliği yapabilirler (1-3)

Yüksek plazma lipidlerinin (kolesterol ya da trigliseritler) deri, tendonlar, göz, karaciğer ve dalak gibi çeşitli dokularda makrofajlar içerisinde birikerek depolanmaları fizik muayenede kolayca fark edilebilirler ve bu birikimler, lipid düşürücü tedavi ile neredeyse tamamen düzelirler $(3,4)$. Hipertrigliseridemi, erişkin dönemde farklı klinik prezantasyonları bulunmasına rağmen nadiren eruptif ksantom bulgusularıyla ortaya çıkabilir.

Burada, şizofreni tanısıyla izlenirken ciltte eruptif ksantomlu döküntüleriyle birlikte diabetes mellitus ve ağır hipertrigliseridemi tanısı alan bir olguyu sunmaktayız.

\section{OLGU SUNUMU}

Otuzdört yaşında bir erkek hasta, cilt döküntüleriyle başvurduğu klinikte yapılan kan tetkiklerinde trigliserid yüksekliği nedeni ile ileri tetkik ve tedavi için endokrinoloji polikliniğine yönlendirilmişti. Hastanın bir ay önce kol, bacak ve gövdesinde ciltte giderek sayısı artan sarımsı renkli, deriden kabarık, kaşıntılı ve ağrılı döküntüleri ortaya çıkmış. Poliklinikte yapılan tetkiklerinde trigliserit kan düzeyi çok yüksek saptanmıştı. Özgeçmişinde şizofreni tanisı mevcut olan hasta ketiapin fumarat $1 \times 100 \mathrm{mg} /$ gün peroral ve 15 günde bir risperidon 1 x $50 \mathrm{mg}$ intramüsküler kullanmaktaydı. Yaklaşık dört yıldır günde bir paket sigara kullanımı vardı. Soygeçmişinde dedesinde diabetes mellitus ve hipertansiyon, babaannesinde koroner arter hastalığ 1 ve annesinde mide karsinomu vardi. Sistem sorgulamasinda uyku bozukluğu, iştah artışı, sık idrara çıkma, gece idrara çıkma, idrar kaçırma, ağız kuruluğu, çok su içme, terleme,sinirlilik ve son dört ayda $15 \mathrm{~kg}$ kilo kaybı mevcuttu. Fiziki muayenesinde genel durumu iyi, boyu $175 \mathrm{~cm}$, ağırlığı $105 \mathrm{~kg}$, beden kütle indeksi $34,2 \mathrm{~kg} / \mathrm{m}^{2}$, bel çevresi $112 \mathrm{~cm}$, kan basınc1 140/90 mmHg, nabız dakika sayısı 80/ritmikti.
Yapılan fizik muayenesinde sırtta, göğüste, ve ekstremitelerin ekstansör yüzeylerinde çok sayıda 1-3 mm çaplı sarı papüller, palmar bölgede deri kıvrımları boyunca çizgisel sarı renk değişikliği saptandı. Gövde ve ekstremite lezyonları eruptif ksantom, avuç içi lezyonlar ise palmar ksantom olarak değerlendirildi. Obezite, hiperlipidemi, diabetes mellitus ve şizofreni tanılarıyla yapılan tetkiklerinde belirgin trigliserid yüksekliği saptandı (Tablo 1). Serumu bulanık ve yağlı görünümlüydü. (Şekil 1). Karaciğer fonksiyonları, böbrek fonksiyonları ve elektrokardiyografi normaldi. Hastanın albuminürisi mevcuttu. Beslenme düzeni ve içeriğinde düzenlemeler, günlük egzersiz süresi ve sıklığında artış ile ağırlı̆̆ın azaltılması sağlandı. Metabolizmanın kontrolüne yönelik insülin infuzyonu, subkutan düşük molekül ağırlıklı heparin, asetil salisilik asit, insülin duyarlaştırıcı metfomin ve pioglitazon $3 \times 15 / 850 \mathrm{mg}$, mikronize fenofibrat $1 \times 267 \mathrm{mg}$, atorvastatin $1 \times 20 \mathrm{mg}$, omega- 3 yağ içeren preparattan $3 \times 1$ gr ve albuminüri için ramipril $1 \times 2.5 \mathrm{mg}$ peroral başlandı. Hiperlipidemiyi artırıcı etkisinden ötürü antipsikotiklerin dozu ayarlandı. Yaklaşık iki hafta içinde kan trigliserid düzeyleri $9340 \mathrm{mg} / \mathrm{dl}$ seviyelerinden $1092 \mathrm{mg} / \mathrm{dl}$ seviyelerine indi. Eruptif ksantomlar solmaya başladı ve kaşıntı şikayeti geriledi. Kan şekeri kontrolü sağlanan hasta ayaktan takibe alındi.

Tablo 1: Olgumuzun laboratuvar değerleri

\begin{tabular}{|c|c|c|}
\hline Laboratuvar parametreleri & Sonuç & Normal sınırları \\
\hline Lökosit sayısı (sayı/mm³) & 7200 & $4800-10800$ \\
\hline Hemoglobin $(\mathrm{g} / \mathrm{dl})$ & 18,6 & $12-18$ \\
\hline Trombosit (sayı $/ \mathrm{mm}^{3}$ ) & 359000 & $140000-400000$ \\
\hline Nötrofil (say1/ $\left./ \mathrm{mm}^{3}\right)$ & 3800 & $2200-4800$ \\
\hline Açlık kan glukozu mg/dl & 245 & $70-110$ \\
\hline Gilikolize hemoglobin (\%A1C) & 11,1 & $4,00-5,90$ \\
\hline Trigliserid $(\mathrm{mg} / \mathrm{dl})$ & 9340 & $<150$ \\
\hline HDL-kolesterolü (mg/dl) & 38 & $40-100$ \\
\hline LDL-kolesterolü mg/dl & 137 & $<130$ \\
\hline Alanin transaminaz $(\mathrm{U} / \mathrm{L})$ & 35 & $<41$ \\
\hline Kreatinin $(\mathrm{mg} / \mathrm{dl})$ & 0,4 & $<1,4$ \\
\hline Trotropin, TSH (uIU/ml) & 1,46 & $0,27-4,2$ \\
\hline Serbest T4 (ng/dl) & 1,24 & $0,93-1,7$ \\
\hline $\operatorname{Amilaz}(\mathrm{U} / \mathrm{L})$ & 22 & $28-100$ \\
\hline Lipaz (U/L) & 27 & $13-60$ \\
\hline Gama glutamil transferaz (U/L) & 154 & $8-61$ \\
\hline Sodyum $(\mathrm{mEq} / \mathrm{L})$ & 127 & $135-145$ \\
\hline Potasyum (mEq/L) & 3,8 & $3,5-5,5$ \\
\hline
\end{tabular}

HDL: High density lipoprotein (yüksek dansiteli lipoprotein), LDL: Low density lipoprotein (düşük dansiteli lipoprotein) 


\section{TARTIŞMA}

Hiperlipidemi, lipid metabolizmasının primer bozukluğu şeklinde veya sekonder bozukluklara bağlı olarak görülebilmektedir. Primer bozukluklar tek başına hiperkolesterolemi ve hipertrigliseridemi veya hiperkolesterolemi+hipertrigliseridemi kombinasyonu ve HDL kolesterol düşüklüğü şeklinde seyredebilmektedir. Sekonder bozukluklar ise diabetes mellitus, nefrotik sendrom, hipotroidizm, alkolizm, kronik karaciğer hastalığı (obstruktif), protein yapı bozuklukları ve bazı ilaçlarla uzun süren ilaç tedavileri (oral kontraseptifler, tiazid diüretikler, antipsikotikler ve glukokortikoidler) sonucu ortaya çıkmaktadır. Hiperlipideminin teşhisi için 20 yaş üstü bireylerde her beş yılda bir serum lipid düzeyi ölçümü gerekmektedir (1-3). Olgumuzda ciltte kaşıntı ve döküntülerin nedeni araştırılırken trigliserid düzeylerinin çok yüksek olduğu saptanmıştır. Hiperlipidemiye neden olabilecek ya da artıracak obezite ve antipsikotik kullanımı da olgumuzda dikkat çekiciydi. Ayrıca ortaya çıkan glisemik regülasyondaki bozukluk önemli nedenlerden biri olmuştur. Olgumuz pankreatit ve koroner arter hastalığı açısından yüksek riskli olduğu bir klinik tablo içerisindedir. Pankreatit ve koroner arter hastalığı henüz saptanmamıştır. $\mathrm{Bu}$ durum tedaviye hızla başlayarak trigliserid seviyeleri kritik düzeylerden uzaklaştırılmıştır.

Ksantomlar, deride bulunan histiyositlerde lipit birikimleri sonucu oluşur. Kanda normal lipit seviyeleri (normolipemi) veya artmıs serum lipit seviyeleri (hiperlipidemi) ile birlikte görülebilir. Lipit içeren histiyositler karakteristik olarak "köpüklü" görünümündedirler. Lipidlerin ekstrasellüler depolandığ 1 ve dermal histolitik inflamasyonun bir klinik görünümüdür. Eruptif ksantom; sırtta, göğüste ve ekstremite proksimallerinde 1-3 $\mathrm{mm}$ boyutunda sarı papüller olarak; ise avuç içi çizgileri boyunca lineer sarı diskolerasyon şeklinde karşımıza çıkar $(4,5,8)$. Ksantomların klinik tanısı kolaydır. Yaygın ksantom varlığında psödoksantom, Langerhans hücreli histiositoma ortaya çıkan histiyositlerin nokta benzeri görünümler, yabancı cisimler ve depo hastalıklarını ayırt etmek gerekir (8). Tedavi primer hastalığın tedavisi şeklindedir. Erken tedavi ile lipidlerin kanda düşüklüğü deri lezyonlarının da çekilmesini sağlar. Medikal tedavi yetersiz olursa cerrahi, lazer ya da kriyocerrahi gibi farklı yöntemler uygulanabilir (4). Olgumuzda olduğu gibi yetişkin bireylerde genetik lipid bozukluğundan daha çok sekonder nedenler sorumludur. Hipertrigliseridemiye yönelik tedavi ile eruptif ksantomlar da geriledi.

Dislipidemi tedavisinde farmokolojik ajanlar kadar farmakolojik olmayan tedavilerin de önemi büyüktür. Diyet modifikasyonu hiperlipidemi tedavisinin önemli bir unsurudur. Diyette doymuş yağ ve kolesterol kısıtlanmalıdır. Hipertrigliseridemik hastalar icin, basit şekerlerin alımı da azaltılmalıdır. Eğer hastada obezite mevcutsa, obezitenin tedavisi ile plazma lipidlerinde olumlu bir etki gözlenebilir ve bu gibi hastalara mutlaka kilo kontrolü önerilmelidir. İlac tedavisini verme kararı kardiyovasküler riske bağlıdır. Mutlak KVH riski 10 ylllk >\%20 olan hastalar "KVH risk eşdeğeri” olarak değerlendirilir ve mutlaka ilaç tedavisi de uygulanmalıdır. Şiddetli hipertrigliseridemide yaşam tarzında modifikasyonlar ve farmakolojik tedavi esasdır. Fibratlar ilk tercih edilenlerdendir ve \% 40 kadar düşüş sağlar. Nikotinik asit, safra asidi bağlayıcıları, omega-3 yağ asitleri etkilidir $(9,10)$. Akut pankreatit kliniğinde plazmaferez hızlı düzelme sağlar (11). Beraberinde diyabet, hipotiroidizm ve benzeri sekonder nedenlerin de tedavi edilmesi gerekir. Olgumuzda fibrik asit derivesi,
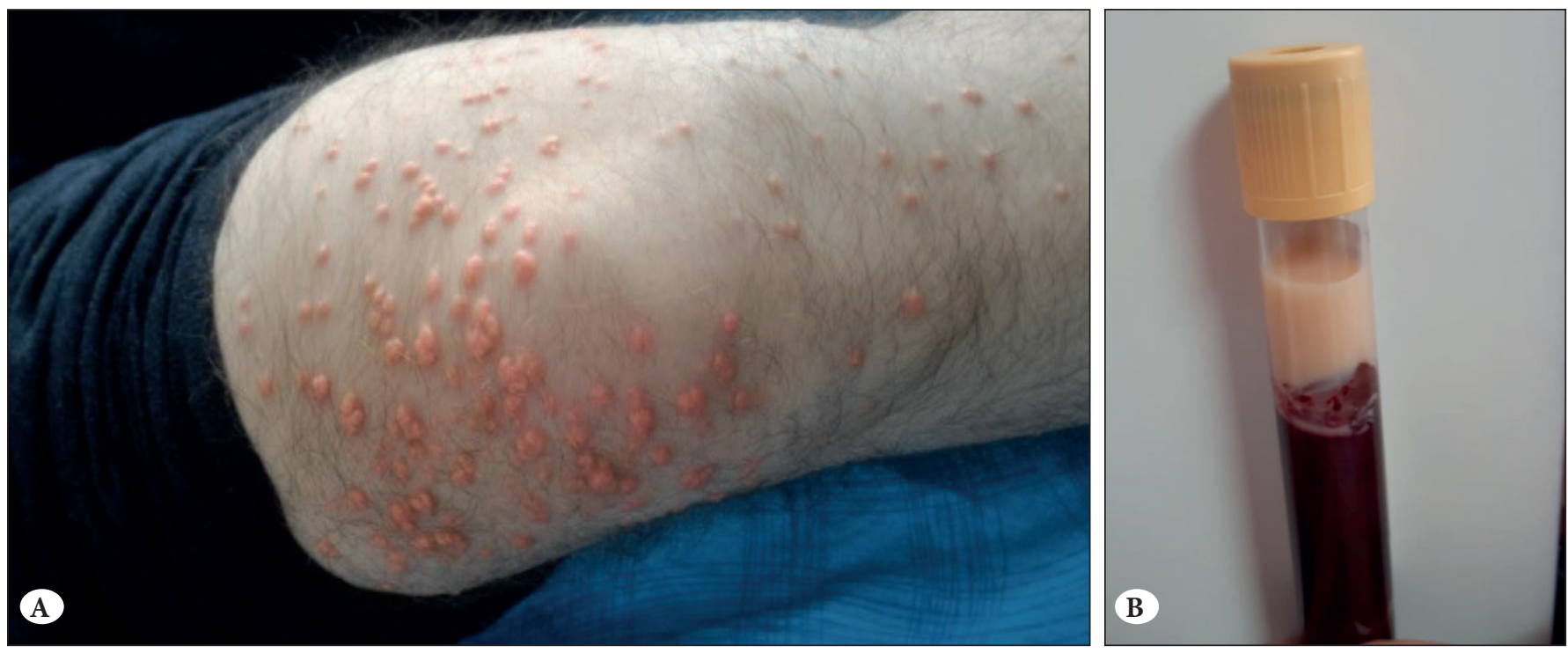

Şekil 1: Hiperlipidemi saptanan olgumuzun ekstiremitesinde A) Eruptif ksantomlar ve B) Bulanık serum görüntüleri 
insülin, heparin, omega-3 yağ asitleri, asetil salisilik asit ile trigliserid seviyelerinde belirgin düzelme sağlanmıştır. İleri tedavi yöntemlerinden plazmafereze ihtiyaç duyulacak bir pankreatit bulgusu saptanmamıştır.

Aterosklerotik damar hastalığ 1 tespit edilmesi, pankreatit, ksantom veya ksantalezma görülmesi ya da yüksek plazma lipid seviyelerinin fark edilmesi üzerine başvuran her hastada öykü ve fizik muayeneyi takiben koroner kalp hastalığ 1 açısından bireysel risk faktörlerinin değerlendirilmesi ve plazma lipidlerinin ölçülmesi gereklidir. Olgumuzda da görüldüğü gibi hiperlipidemiler genetik alt yapısı müsait bireylerde obezite, diabetes mellitus ve antipsikotiklerle belirgin ortaya çıkabilirler. Prezantasyonları nadir bir bulgu olan eruptif ksantomlar şeklinde olabilir. Bu gibi olgulara metabolik yolaklara yönelik çok yönlü yaklaşımla lipid aferezi gerektirmeden etkin sonuçlar elde edilebilir.

\section{KAYNAKLAR}

1. Kushner PA, Cobble ME. Hypertriglyceridemia: The importance of identifying patients at risk. Postgrad Med. 2016;128(8):848-858.

2. Fredrickson DS, Lee RS. A system for phenotyping hyperlipidemia. Circulation. 1965;31:321-327.

3. Ginsberg Hn. Diabetic dyslipidemia: Basic mechanisms underlying the common hypertriglyceridemia and low hdl cholesterol levels. Diabetes. 1996; 45(Suppl 3):S27-S30.
4. Zaremba J. Zackiewicz A, Placek W. Eruptive xanthomas. Postep Derm Alergol. 2013;30(6):399-402.

5. Bito T, Kawakami C, Shimajiri S, Tokura Y. Generalized eruptive xanthoma with prominent deposition of naked chylomicrons: Evidence for chylomicrons as the origin of urate-like crystals. J Cutan Pathol. 2010;37:1161-1163.

6. Henning JS, Fazio MG. Yellowish papules on a middle-aged man. Eruptive xanthoma. Am Fam Physician. 2011;83:73-74.

7. Ladizinski B, Lee KC. Eruptive xanthomas in a patient with severe hypertriglyceridemia and type 2 diabetes. CMAJ. 2013; 185:1600.

8. Vangara SS, Klingbeil KD, Fertig RM, Radick JL. Severe hypertriglyceridemia presenting as eruptive xanthomatosis. J Family Med Prim Care. 2018;7(1):267-270.

9. Kayaalp O. Hipolipidemik İlaçlar: Kayaalp O, ed. Rasyonel Tedavi Yönünden Tıbbi Farmakoloji. Ankara, Hacettepe TAŞ Kitapçılık Ltd Şti, 2000: 1. cilt, 8.baskı, 567-587.

10. Hegele RA, Ginsberg HN, Chapman MJ, Nordestgaard BG, Kuivenhoven JA, Averna M, et al. The polygenic nature of hypertriglyceridaemia: Implications for definition, diagnosis, and management. Lancet Diabetes Endocrinol. 2014;2:655666.

11. Valdivielso P, Ramírez-Bueno A, Ewald N. Current knowledge of hypertriglyceridemic pancreatitis. Eur J Intern Med. 2014;25:689-694 